\title{
Effects of Test Temperature on Internal Fatigue Crack Generation Associated with Nonmetallic Particles in Austenitic Steels
}

\begin{abstract}
OSAMU UMEZAWA and KOTOBU NAGAI
Internal crack generation associated with nonmetallic inclusions or precipitates has been investigated on high-cycle fatigue at $4 \mathrm{~K}, 77 \mathrm{~K}$, and $293 \mathrm{k}$ of $25 \mathrm{Mn}-5 \mathrm{Cr}$ high-manganese austenitic steel and nitrogen-strengthened $25 \mathrm{Cr}-13 \mathrm{Ni}$ austenitic stainless steel. In both steels, the internal crack initiation typically occurred at $4 \mathrm{~K}$ or in long-life range over $10^{6}$ cycles at $77 \mathrm{~K}$. Particles such as inclusions and precipitates were responsible for the internal crack-generation behavior, and the origins were identified as mainly $\mathrm{Al}_{2} \mathrm{O}_{3}$ inclusions in $25 \mathrm{Mn}-5 \mathrm{Cr}$ steel and $\mathrm{AlN}$ precipitates in $25 \mathrm{Cr}-13 \mathrm{Ni}$ steel, respectively. We discuss the crack-generation stage I mechanism and the relationship between stress range and size of crack-initiation site. The generation of fatigue cracks associated with the nonmetallic particles in the specimen interior involved a stage I crack. A threshold condition assumption was proposed, that the crack propagation occurred at any stress level when the local stress intensity factor range reached over a constant at or around the initiation crack associated with defects.
\end{abstract}

\section{INTRODUCTION}

THE generation of subsurface (internal) fatigue cracks in high-strength alloys is usually associated with the presence of nonmetallic inclusions, as illustrated in the case of fish-eye-type fractures. ${ }^{[1,2]}$ While the mechanism of the crack generation and its growth originating from a nonmetallic inclusion near the specimen surface has been discussed, ${ }^{[3,4]}$ it has not been sufficient to understand the internal crack-generation mechanism associated with preexisting defects, such as inclusions. Table I provides a summary of our results ${ }^{[5-10]}$ on the fatigue crack-initiation site and subsurface crack origin at cryogenic temperatures. Subsurface crack initiation is dominant at lower temperatures and in the long-life range, while surface crack initiation occurs in high peak stress tests or in short-life tests. For example, the Ti-6Al-4V alloys and $24 \mathrm{Cr}-15 \mathrm{Ni}-4 \mathrm{Mn}-0.3 \mathrm{~N}$ steel listed in Table I have the highest strength level among the cryogenic structural alloys, and their subsurface crack initiation apparently occurs due to transgranular or intergranular cracking. ${ }^{[6,9]}$ The dependence of subsurface crackinitiation site size on the peak stress was able to be accounted for by a threshold condition assumption such that microcracks grew until a critical crack size depending on the peak stress.

Furthermore, the possibility that, even in an S-N curve, different crack initiation mechanisms can exist has not been focused. For an A2219 alloy, two types of internal crack initiation origins, of which were precipitate and intergranular cracking, were detected at cryogenic temperatures. ${ }^{[10]}$ This means that the microcrack originating from a pre-existing defect may not always provide a critical crack size. In order to determine the defect that is finally responsible for fatigue failure, not only the metallurgical origin but also

OSAMU UMEZAWA, Senior Scientist, and KOTOBU NAGAI, Unit Leader, are with the Frontier Research Center for Structural Materials, National Research Institute for Metals, Ibaraki 305-0047, Japan.

Manuscript submitted April 29, 1997. the geometry of the initial cracks have to be discussed. Hence, the metallurgical and micro-fractographical investigations are necessary to clarify the mechanism of internal crack generation from defects such as nonmetallic particles.

The internal crack initiation in high-cycle fatigue has been detected in $25 \mathrm{Mn}-5 \mathrm{Cr}$ high-manganese austenitic steel and nitrogen-strengthened $25 \mathrm{Cr}-13 \mathrm{Ni}$ austenitic stainless steel at cryogenic temperatures. For the $25 \mathrm{Mn}-5 \mathrm{Cr}$ steel, in which the important role of inclusions on its fatigue crackgrowth behavior was already reported elsewhere, ${ }^{[11]}$ the internal crack initiation associated with nonmetallic inclusions was dominant at cryogenic temperature. ${ }^{[8]}$ The $25 \mathrm{Cr}-13 \mathrm{Ni}$ steel also contained fine particles. ${ }^{[12]} \mathrm{In}$ the present study, the internal crack generation in each steel has been characterized. Special attention is given to present the important role of nonmetallic particles at initiation sites for the microcracking and its growth.

\section{EXPERIMENTAL}

\section{A. Materials and Fatigue Test Conditions}

Two kinds of austenitic steels in solution-treated condition, $25 \mathrm{Mn}-5 \mathrm{Cr}^{[13]}$ and nitrogen-strengthened $25 \mathrm{Cr}-13 \mathrm{Ni},{ }^{[12]}$ were examined. The chemical compositions of each steel are listed in Table II. The $25 \mathrm{Mn}-5 \mathrm{Cr}$ steel was hot rolled (heating at $1473 \mathrm{~K}$ ) into 30 -mm-thick plate and solution treated at $1323 \mathrm{~K}$. The $25 \mathrm{Cr}-13 \mathrm{Ni}$ steel was also hot rolled into 30-mm-thick plate and solution treated. Figure 1 shows optical microstructures for each steel. The $25 \mathrm{Mn}-5 \mathrm{Cr}$ steel contains inclusions that are aligned along the rolling direction (RD), as shown in Figure 1(a). The existence of $\mathrm{Al}_{2} \mathrm{O}_{3}$ inclusions was confirmed by an $\mathrm{X}$-ray microprobe analysis. For the $25 \mathrm{Cr}-13 \mathrm{Ni}$ steel, no inclusion is visible in Figure 1(b), but it contained the fine particles with 0.076 pct in volume where the nonmetallic inclusions (such as $\mathrm{Al}_{2} \mathrm{O}_{3}$, $\mathrm{CaO}$, and $\mathrm{CaS}$ ), and the precipitate (such as $\mathrm{AlN}$ ) were detected. The inclusions and their volume fraction were determined by a computer aided macroanalysis. 
Table I. Summary of Crack Initiation Site and Subsurface Crack Origin for the Tested Materials

\begin{tabular}{|c|c|c|c|c|c|}
\hline \multirow[b]{2}{*}{ Materials } & \multicolumn{3}{|c|}{$\begin{array}{l}\text { Crack Initiation Site } \\
\left(10^{4} \text { to } 10^{7} \text { cycles }\right)\end{array}$} & \multirow[b]{2}{*}{ Subsurface Crack Origin } & \multirow[b]{2}{*}{ References } \\
\hline & $293 \mathrm{~K}$ & $77 \mathrm{~K}$ & $4 \mathrm{~K}$ & & \\
\hline \multicolumn{6}{|l|}{ Titanium alloy (mill annealed) } \\
\hline Ti-5Al-2.5Sn extra low interstitials & $\mathrm{S}$ & $\mathrm{S}$ & $\mathrm{S}>\mathrm{I}$ & transgranular (fine $\alpha$ phase) & 5 \\
\hline Ti-6Al-4V forged & $\mathrm{S}>\mathrm{I}$ & $\mathrm{S}>\mathrm{I}$ & $\mathrm{S}>\mathrm{I}$ & transoranular ( $\alpha$ phase) & 6 \\
\hline Ti-6Al-4V forged + rolled & $\mathrm{S}>\mathrm{I}$ & $\mathrm{S}>\mathrm{I}$ & $\mathrm{S}>\mathrm{I}$ & transgranuiar ( $\alpha$ pnase) & 6 \\
\hline \multicolumn{6}{|l|}{ Austenitic steel (solution treated) } \\
\hline SUS316LN & S & $\mathrm{S}$ & $\mathrm{S}>\mathrm{I}$ & pore & 8 \\
\hline SUS316LN +20 pct cold rolled & $\mathrm{S}$ & $\mathrm{S}>\mathrm{I}$ & I & Cr, Mo-rich zone & 8 \\
\hline $32 \mathrm{Mn}-7 \mathrm{Cr}-0.1 \mathrm{~N}$ & $\mathrm{~S}$ & $\mathrm{~S}>\mathrm{I}$ & I & intergranular & 9 \\
\hline $24 \mathrm{Cr}-15 \mathrm{Ni}-4 \mathrm{Mn}-0.33 \mathrm{~N}$ & $\mathrm{~S}>\mathrm{I}$ & $\mathrm{S}>\mathrm{I}$ & $\mathrm{S}>\mathrm{I}$ & intergranular & 9 \\
\hline \multicolumn{6}{|l|}{ Aluminum alloy } \\
\hline A2219-T87 & $\mathrm{S} / \mathrm{I}$ & $\mathrm{S} / \mathrm{I}$ & $\mathrm{S} / \mathrm{I}$ & precipitate or intergranular & 10 \\
\hline
\end{tabular}

Table II. Chemical Compositions of Tested Steels in the Present Study

\begin{tabular}{|c|c|c|c|c|c|c|c|c|c|c|c|c|c|c|c|}
\hline \multirow[b]{2}{*}{ Steels } & \multicolumn{15}{|c|}{ Concentration (Mass Pct) } \\
\hline & $\mathrm{C}$ & $\mathrm{P}$ & $\mathrm{Si}$ & S & Mn & $\mathrm{Ni}$ & $\mathrm{Cr}$ & Mo & $\mathrm{Al}$ & $\mathrm{Nb}$ & $\mathrm{N}$ & $\mathrm{Ca}$ & $\mathrm{Ti}$ & $\mathrm{O}$ & $\mathrm{Fe}$ \\
\hline $25 \mathrm{Mn}-5 \mathrm{Cr}$ & 0.22 & 0.024 & 0.86 & 0.001 & 25.60 & 0.97 & 4.67 & - & 0.009 & 0.043 & 0.040 & - & - & - & bal \\
\hline $25 \mathrm{Cr}-13 \mathrm{Ni}$ & 0.015 & 0.035 & 1.12 & $<0.001$ & 0.78 & 13.52 & 25.06 & 0.76 & 0.065 & - & 0.368 & 0.002 & $<0.01$ & 0.0030 & bal \\
\hline
\end{tabular}

Table III. Tensile Properties and Toughness of the Tested Steels at Cryogenic Temperatures

\begin{tabular}{|c|c|c|c|c|c|c|c|}
\hline Steel & $\begin{array}{c}\text { Temperature } \\
(\mathrm{K})\end{array}$ & $\begin{array}{l}\text { UTS } \\
(\mathrm{MPa})\end{array}$ & $\begin{array}{c}\mathrm{YS} \\
(\mathrm{MPa})\end{array}$ & $\begin{array}{c}\mathrm{El} \\
(\mathrm{Pct})\end{array}$ & $\begin{array}{l}\text { RA } \\
\text { (Pct) }\end{array}$ & $\begin{array}{c}\text { CVN } \\
(\mathrm{J})\end{array}$ & $\begin{array}{c}K_{I C}(\mathrm{~J}) \\
(\mathrm{MPa} \sqrt{\mathrm{m}})\end{array}$ \\
\hline \multirow[t]{3}{*}{$25 \mathrm{Mn}-5 \mathrm{Cr}$} & 4 & 1529 & 958 & 42.3 & 44.0 & 68 & 255 \\
\hline & 77 & 1239 & 619 & 55.7 & 45.1 & 77 & - \\
\hline & 293 & 702 & 364 & 65.1 & 62.7 & 155 & - \\
\hline \multirow[t]{3}{*}{$25 \mathrm{Cr}-13 \mathrm{Ni}$} & 4 & 1886 & 1381 & 18.0 & 45.2 & 60 & 118 \\
\hline & 77 & 1542 & 1024 & 43.8 & 59.6 & 69 & - \\
\hline & 293 & 805 & 428 & 51.3 & 64.7 & 177 & - \\
\hline
\end{tabular}

\footnotetext{
*Temp: temperature; UTS: ultimate tensile strength; YS: 0.2 pct proof stress; El: elongation; RA: reduction of area; and CVN: Charpy absorbed energy.
}

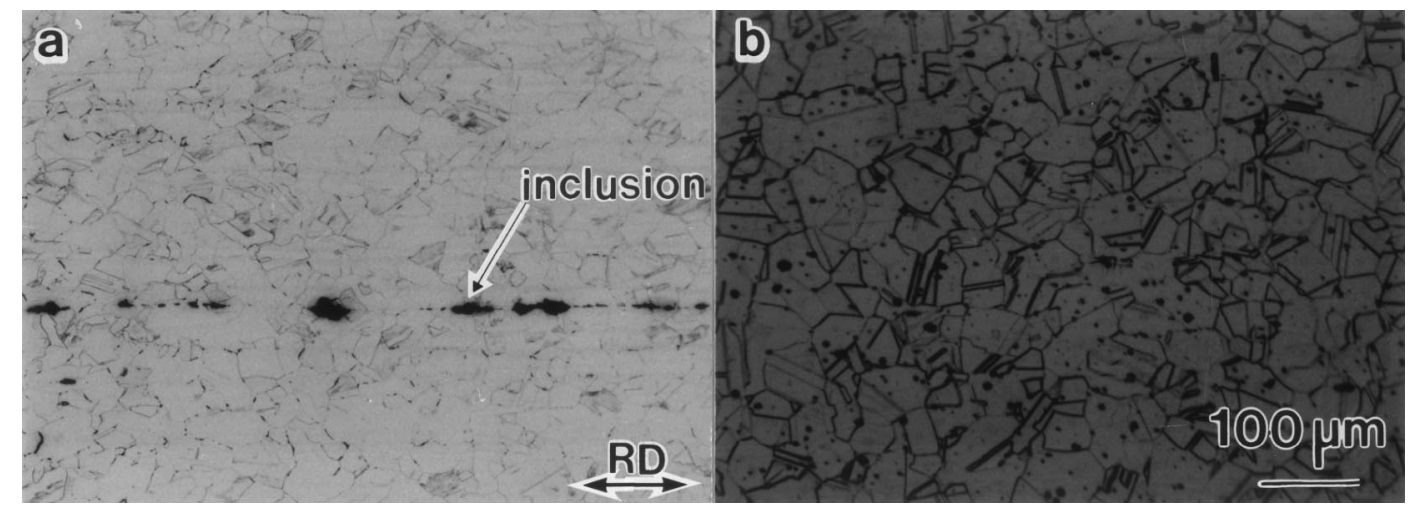

Fig. 1-Optical microstructures of the transverse section in fatigue specimen: (a) $25 \mathrm{Mn}-5 \mathrm{Cr}$ steel and $(b) 25 \mathrm{Cr}-13 \mathrm{Ni}$ steel.

Fatigue test conditions were as follows: hourglass-type unnotched specimens with a reduced diameter of $6 \mathrm{~mm}$ were fatigued in liquid helium $(4 \mathrm{~K})$, liquid nitrogen (77 $\mathrm{K})$, and air $(293 \mathrm{~K})$. The longitudinal direction of the spec- 


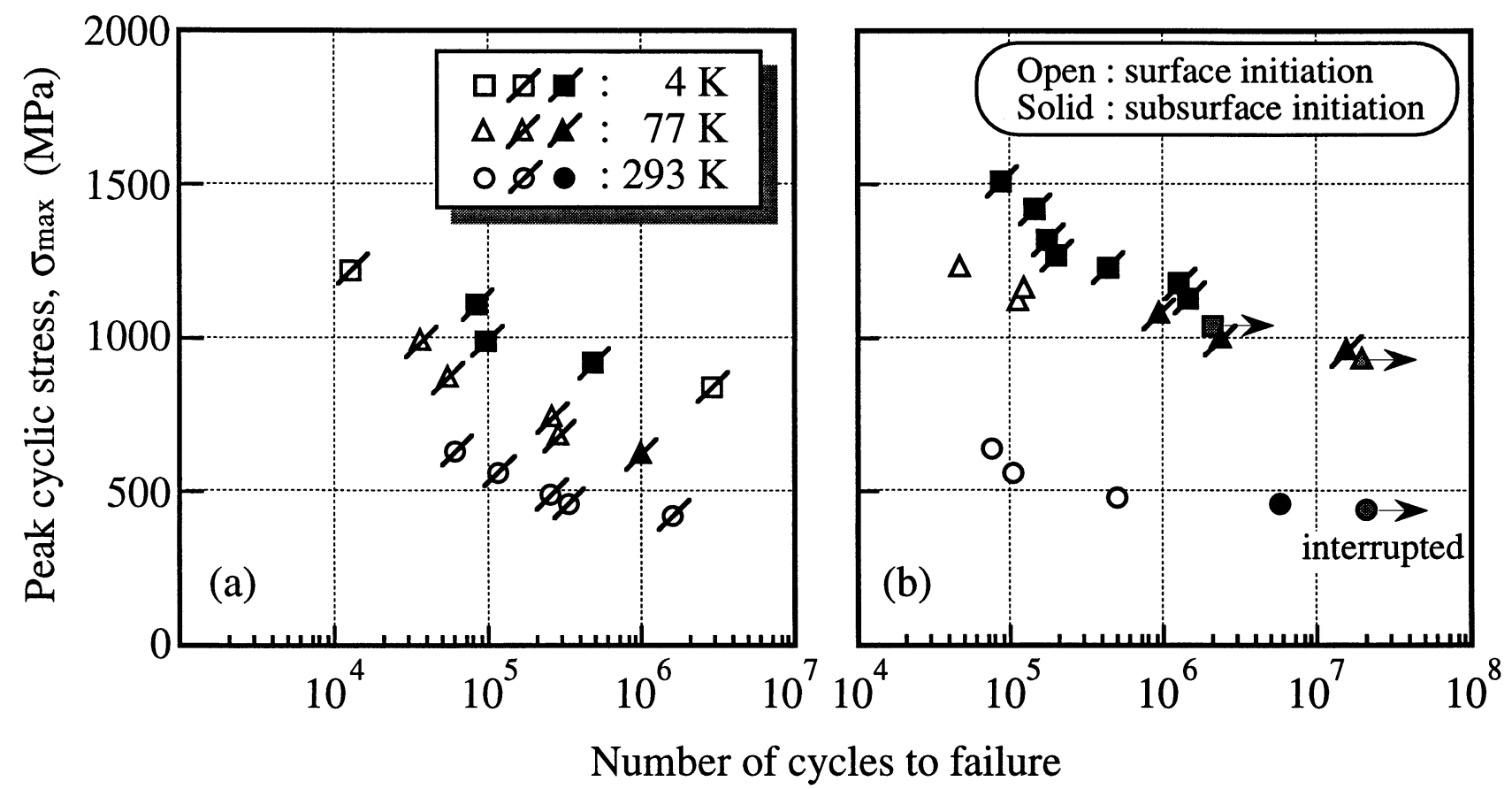

Fig. 2-S-N data of (a) 25Mn-5Cr and (b) 25Cr-13Ni steels at cryogenic temperatures. Slanting bars in each plot indicate the crack initiation in conjunction with nonmetallic particles.
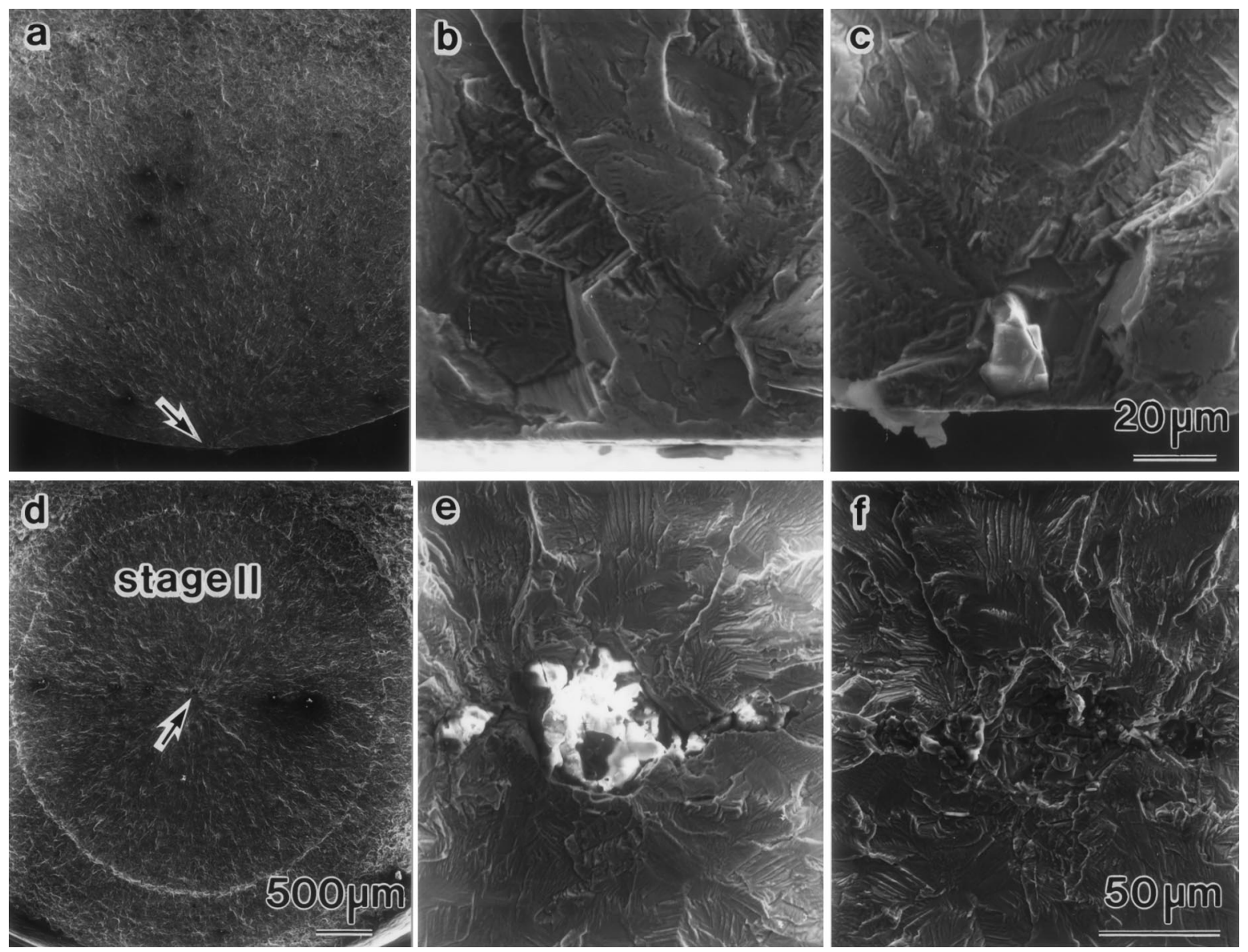

Fig. 3-SEM micrographs of fatigue fracture surfaces and crack initiation sites for $25 \mathrm{Mn}-5 \mathrm{Cr}$ steel at $4 \mathrm{~K}:(a)$ through $(c) \sigma_{\max }=841 \mathrm{MPa}, N f=2,943,880$ cycles; and $(d)$ through $(f) \sigma_{\max }=917 \mathrm{MPa}, N f=473,600$ cycles. Photographs (b) and (c) are matching halves at the crack initiation site in photograph (a). Photographs (e) and (f) are also matching halves at the crack initiation site in photograph(d). 


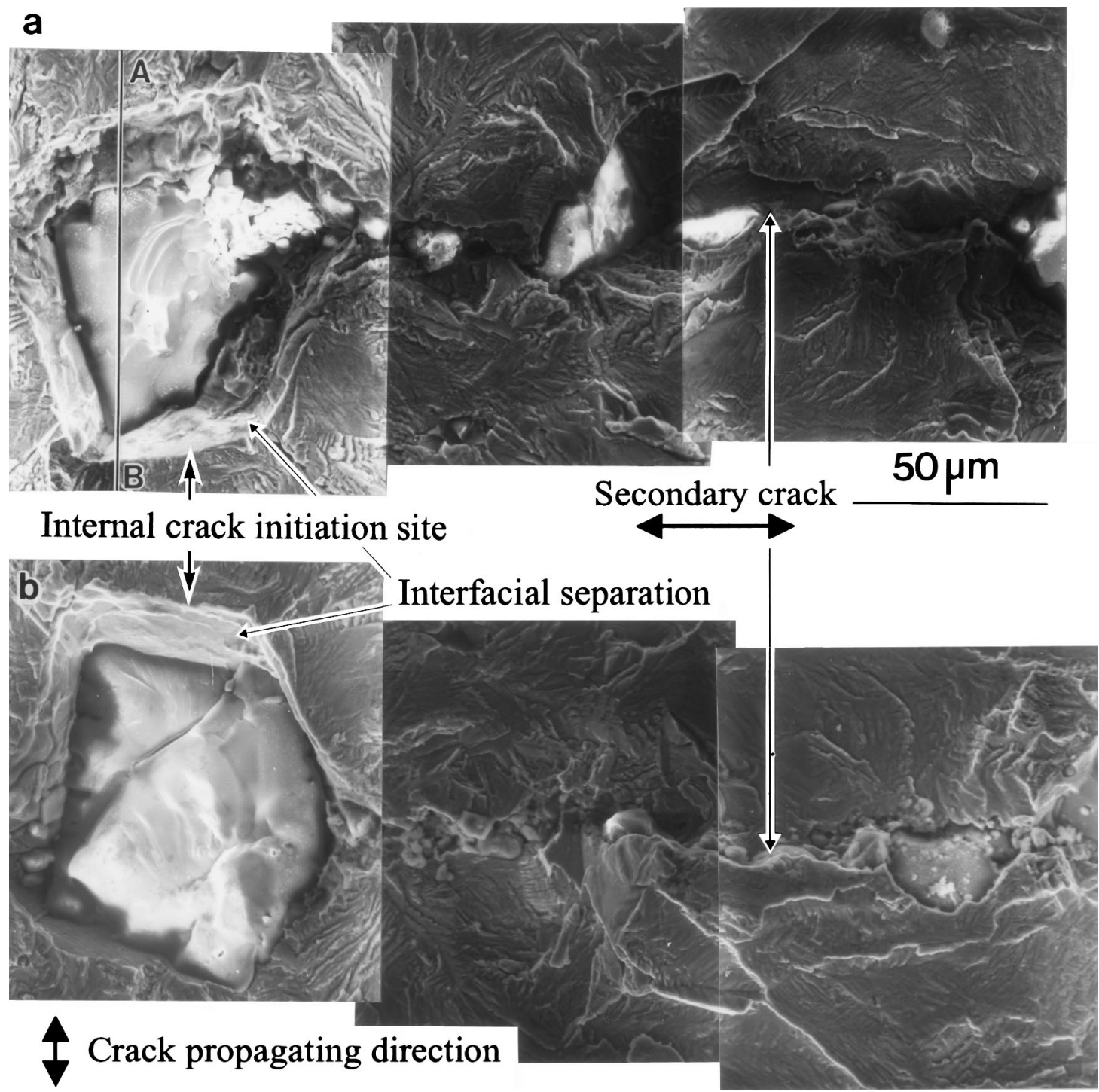

Fig. 4-The internal crack initiation site of sample failed at $4 \mathrm{~K}$ for the $25 \mathrm{Mn}-5 \mathrm{Cr}$ steel $\left(\sigma_{\max }=994 \mathrm{MPa}, N f=97,100\right.$ cycles $)$. SEM micrographs $(a)$ and $(b)$ are matching halves of fracture surfaces. Photograph $(c)$ shows the A-B section shown in photograph (a). Illustration $(d)$ describes the debonding and cracking at the internal crack initiation site in the longitudinal section.

imens was perpendicular to the RD for each steel. The specimen surface was ground and polished. Using the cryogenic servo-hydraulic fatigue testing machine, ${ }^{[14]}$ load-control tests were done with a sinusoidal waveform and a minimum-to-maximum stress ratio $R$ of 0.01 . Testing frequency was $4 \mathrm{~Hz}$ at $4 \mathrm{~K}, 10 \mathrm{~Hz}$ at $77 \mathrm{~K}$, and $20 \mathrm{~Hz}$ at $293 \mathrm{~K} \cdot{ }^{[8,15]}$

\section{B. Microscopy and Characterization}

The fatigue crack-initiation sites were examined by scanning electron microscopy (SEM) with energy dispersive Xray spectroscopy (EDS), laser microscopy (LM), electron probe microanalyzer (EPMA) and scanning Auger multiprobe (SAM), (PHI model 650. The SEM was operated with $20 \mathrm{keV}$ accelerating voltage, and secondary electron images were obtained. The LM, EPMA, and SAM analyses were done in the vicinity of an internal crack-initiation site of $25 \mathrm{Cr}-13 \mathrm{Ni}$ steel, as shown in Figures 5(b) and (c). The LM analysis achieved a three-dimensional characterization of the crack-initiation site, e.g., a birds-eye view and its cross sections. The EPMA was operated with $10 \mathrm{keV}$. The accelerating voltage of the electron probe beam in the SAM was $3 \mathrm{keV}$, and that of Ar ion sputtering was $3 \mathrm{keV}$. To calibrate the results on the internal crack-initiation site, EPMA and SAM analyses were also done for the aluminum, $\mathrm{AlN}$, and $\mathrm{Al}_{2} \mathrm{O}_{3}$ samples. In addition, transmission electron microscopy (TEM) observations were also done to characterize the dislocation structures after fatigue testing.

In this study, we introduced the parameters mentioned later to determine the geometry of the internal crack-initiation site. At first, the internal crack-initiation site was defined as the whole of the inclined area that does not place on the main fatigue crack-propagating plane, as in the previous study. ${ }^{[6]}$ The distance from the internal crack-initiation site to the nearest specimen surface $d$ was evaluated from SEM photographs. The size of the crack-initiation site associated nonmetallic particles was also quantified by a crack-length parameter. The crack size $f_{s}$ was defined as the 

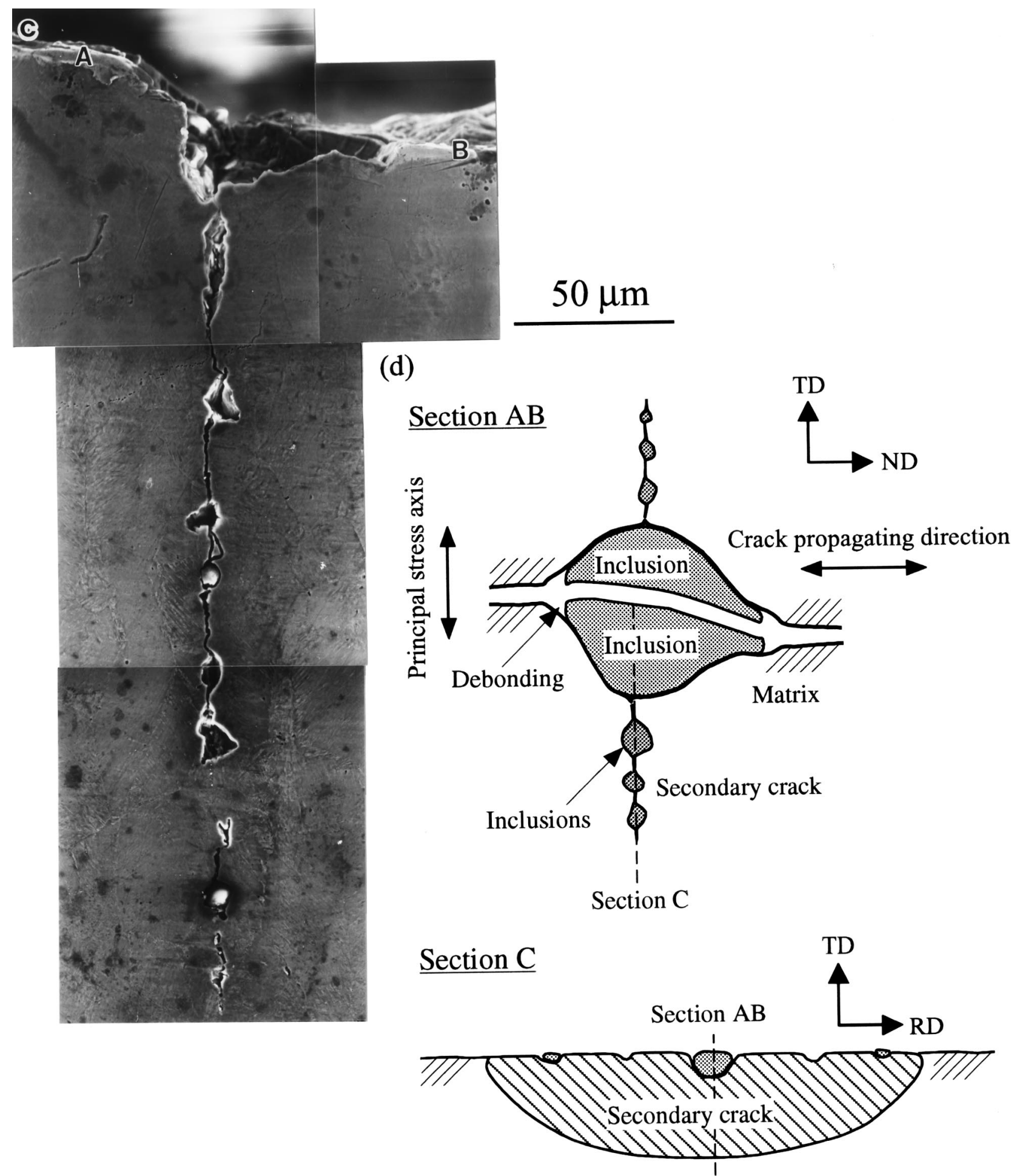

Fig. 4 Continued-The internal crack initiation site of sample failed at $4 \mathrm{~K}$ for the $25 \mathrm{Mn}-5 \mathrm{Cr}$ steel $\left(\sigma_{\max }=994 \mathrm{MPa}, N f=97,100\right.$ cycles). SEM micrographs $(a)$ and $(b)$ are matching halves of fracture surfaces. Photograph $(c)$ shows the A-B section shown in photograph (a). Illustration $(d)$ describes the debonding and cracking at the internal crack initiation site in the longitudinal section.

minor axis of an orthographic projection of the crack-initiation site on the main crack-propagating plane, as in the previous study. ${ }^{[6]}$ In the present study, we apply the parameter $f_{s}$ to the surface crack-initiation site associated with nonmetallic inclusion and to the internal crack-initiation site.

\section{RESULTS}

A. Initiation and Early Growth of Fatigue Crack Originating from Nonmetallic Particle

Figure 2 shows the $\mathrm{S}-\mathrm{N}$ data for $25 \mathrm{Mn}-5 \mathrm{Cr}^{[8]}$ and nitrogen-strengthened $25 \mathrm{Cr}-13 \mathrm{Ni}^{[15]}$ steels, which distinguishes 

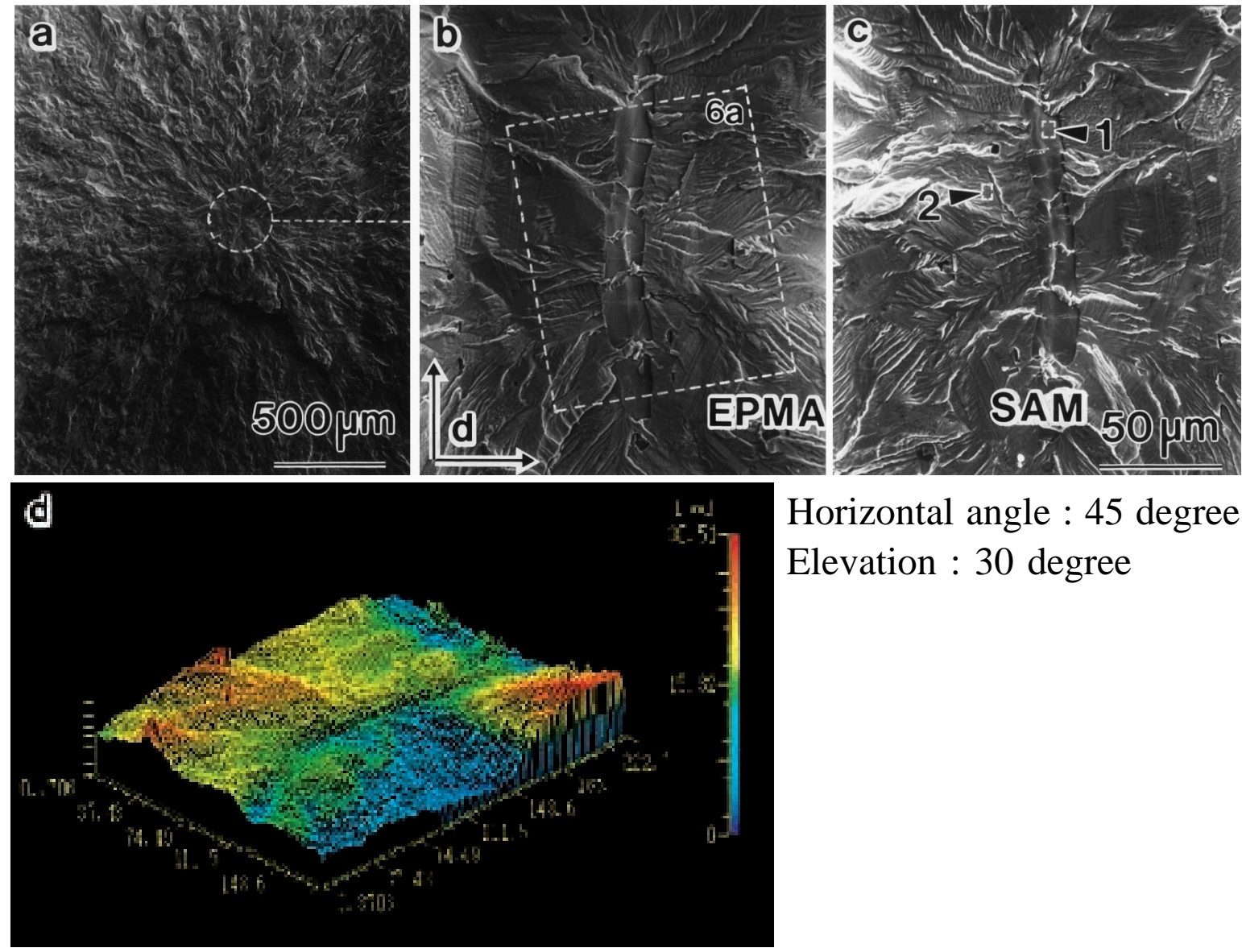

Horizontal angle : 45 degree

Elevation : 30 degree

Fig. 5-The internal crack initiation site of a samplle failed at $4 \mathrm{~K}$ for $25 \mathrm{Cr}-13 \mathrm{Ni}$ steel $\left(\sigma_{\max }=1509 \mathrm{MPa}, N f=88,600\right.$ cycles $)$. Photographs $(b)$ and $(c)$ are matching halves of fracture surfaces. Three-dimensional indication $(d)$ resulting from laser microscopy corresponds to the crack initiation site in photograph (b). The areas marked 1 and 2 represent the SAM analyses region.

each crack-initiation site, whether on the specimen surface (open plots) or on the specimen interior (solid plots). The internal crack initiation is dominant at $4 \mathrm{~K}$ or in longer life range over $10^{6}$ cycles in both steels. The slanting bars in Figure 2 exhibit the fatigue crack initiation due to the nonmetallic inclusion or precipitate, as mentioned below.

\section{25Mn-5Cr high-manganese austenitic steel}

The fatigue crack initiation occurred from the nonmetallic inclusion in all samples, regardless of whether at specimen surface in interior. The internal crack initiation was typically detected at $4 \mathrm{~K}$, as shown in Figure 2(a). Figure 3 shows the fatigue fracture surfaces and crack-initiation sites at $4 \mathrm{~K}$. The fatigue crack is radially propagating from an inclusion in each case, and the ripple mark appears in Figure 3(d). The radius of the stage II region was increased when decreasing the peak cyclic stress. The inclusion related with surface crack initiation was smaller than that associated with internal crack initiation.

The EDS analyses were done for the particular inclusions at which the fatigue crack was initiated. In the inclusions, aluminum was highly enriched, and $\mathrm{Mn}$ and $\mathrm{S}$ were partly detected. Most of the inclusions were identified as $\mathrm{Al}_{2} \mathrm{O}_{3}$.

Figure 4 shows a typical example of the internal crackinitiation site. Micrographs (a) and (b) are matching halves of the fracture surface. The cracking of inclusion or the interfacial separation (debonding) between inclusion and surrounding matrix has occurred at the internal crack-ini- tiation site. The sample shown in Figure 4(a) was sliced vertically at the line A-B. Figure 4(c) shows the plane section A-B of the right side shown in micrograph (a), but the inclusion had already fallen off during sample preparation. The internal crack-initiation site is inclined about 45 deg to the principal stress axis in Figure 4(c) and reveals the transition from the stage I crack to the stage II crack where the crack propagating plane is macroscopically normal to the principal stress axis. In addition, these photographs clearly indicate that the nonmetallic inclusion has only partial contact with the matrix, and that the inclusions link up to form a secondary crack in the plane section $\mathrm{C}$, as illustrated in Figure 4(d). These micrographs revealed the poor adhesion between the nonmetallic inclusion and the matrix. Similar observations were also made in other samples.

\section{Nitrogen-strengthened $25 \mathrm{Cr}$-13Ni austenitic stainless} steel

The internal crack initiation was typically detected at 4 $\mathrm{K}$ or in long-life range above $10^{6}$ cycles in Figure 2(b). Figure 5 represents the internal fatigue crack-initiation site in the $25 \mathrm{Cr}-13 \mathrm{Ni}$ steel failed at $4 \mathrm{~K}$. The internal crack initiation at $4 \mathrm{~K}$ and $77 \mathrm{~K}$ seemed to originate from a brittle cracking of a facet-like form with oval or larger aspect ratio shape, as shown in Figures 5(b) and (c). According to the LM analyses in Figure 5(d), the internal crack-initiation site was macroscopically flat and inclined about $45 \mathrm{deg}$ to the principal stress axis. 

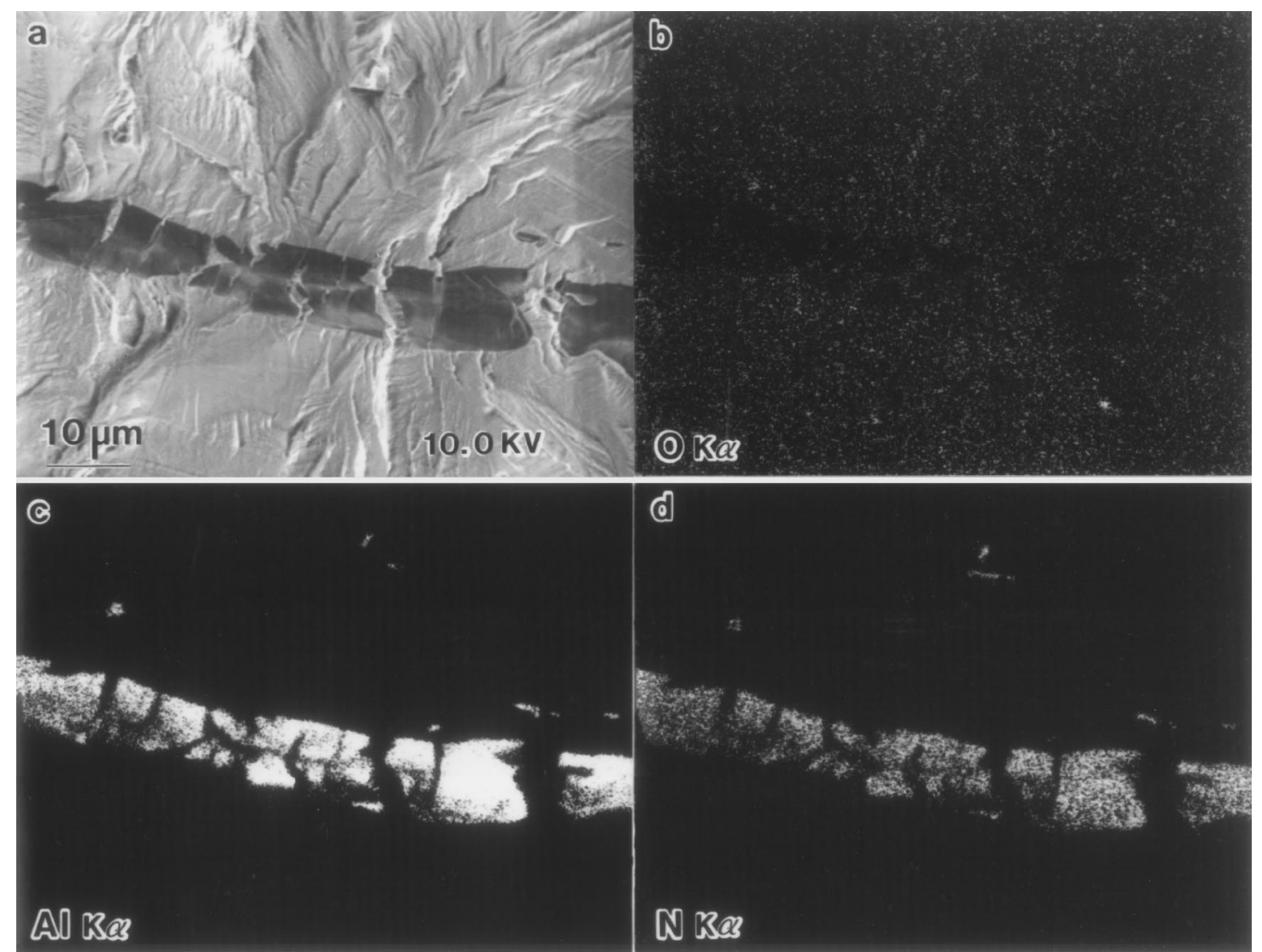

\section{@)}

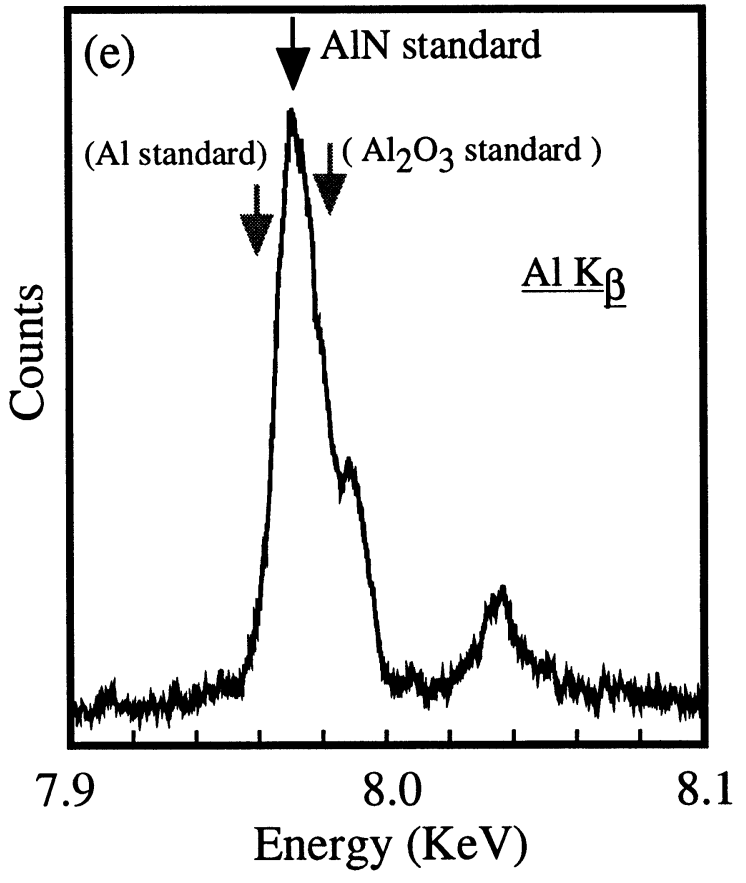

N Res

Fig. 6-EPMA analyses for the internal crack initiation site shown in Fig. 5(b): (a) secondary image of the analyses region; X-ray $\left(K_{\alpha}\right)$ mapping for each element such as $(b) \mathrm{O},(c) \mathrm{Al}$, and $(d) \mathrm{N}$, and (e) $\mathrm{Al} K_{\beta}$ peak energy in a X-ray profile at an $\mathrm{Al}$ enriched point.

Figure 6 represents an EPMA analysis result for the internal crack-initiation site shown in Figure 5(b). Aluminum and nitrogen are detected at the initiation site, and no oxygen was detected. Figure 6(e) shows that $\mathrm{Al}-\mathrm{K}_{\beta}$ peak energy in the X-ray profile is fitted to that of the AIN standard sample-but of neither the metallic aluminum nor the $\mathrm{Al}_{2} \mathrm{O}_{3}$ sample. The sample shown in Figure 5(c) was further analyzed with SAM. Figure 7(a) indicates the change of derivative peak height as a function of $\mathrm{Ar}$ ion sputtering time for $\mathrm{C}, \mathrm{O}, \mathrm{Al}$, and $\mathrm{Fe}$ at the marked area 1 in Figure 5(c). At 120 seconds, 720 seconds, $1.98 \mathrm{ks}$, and $2.82 \mathrm{ks}$, the scan-differentiated spectra in both areas 1 and 2 were obtained. After 250 seconds sputtering, carbon and oxygen (which were absorbed into the specimen surface) disappeared. At area 1, Al was detected until sputtering time of about $2.4 \mathrm{ks}$. The number of counts for $\mathrm{Fe}$ was remarkably increased with a sputtering time above $1.8 \mathrm{ks}$. Figure 7(b) represents the spectrum after 720 seconds sputtering. Both 

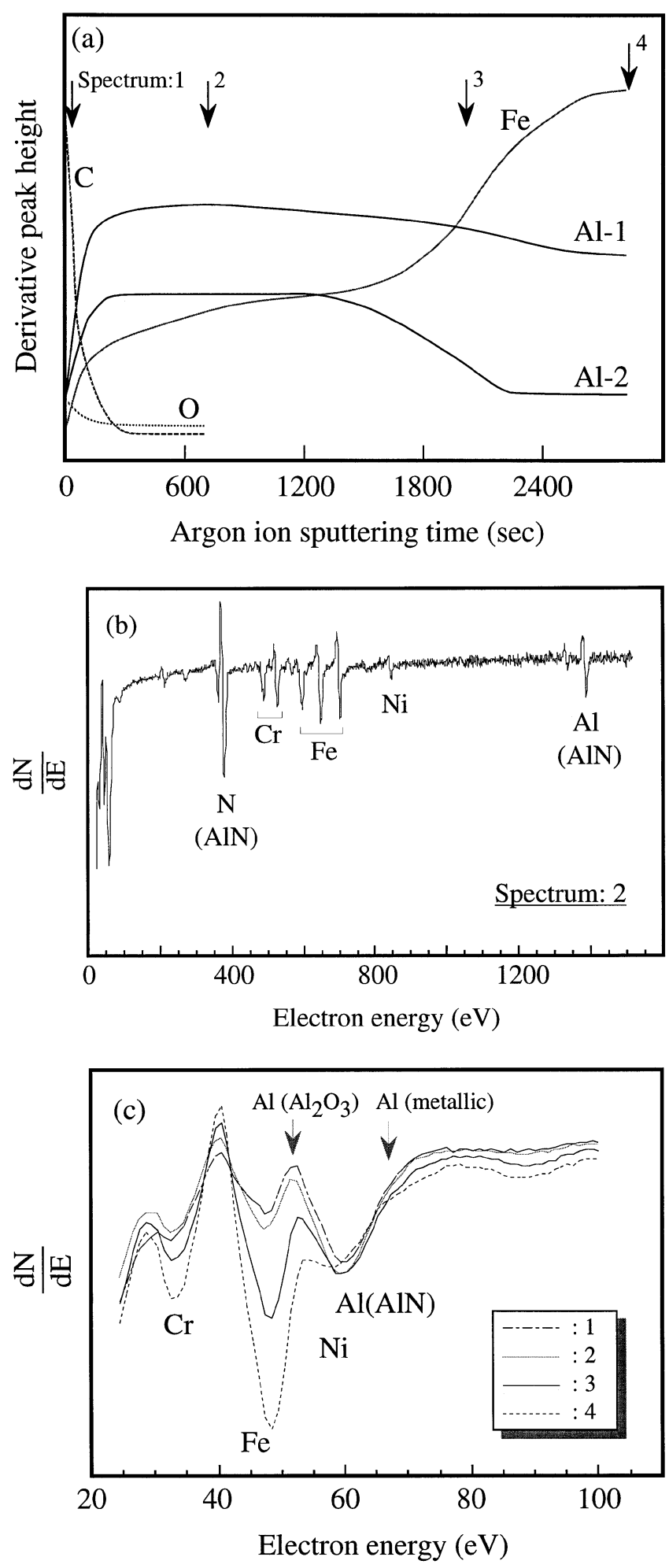

Fig. 7-SAM analyses results at the marked area 1 shown in Fig. 5(c): (a) change of derivative peak height as a function of $\mathrm{Ar}$ ion sputtering time with a smoothing treatment, $(b)$ wide scan differentiated spectrum 2, and $(c)$ change of Auger peak shape in low energy field during $\mathrm{Ar}$ ion sputtering. Arrows in (a) correspond to the points taking each Auger spectrum shown in (c).

peaks of $\mathrm{Al}$ and $\mathrm{N}$ are revealed. The energy of each peak in Figures (b) and (c) is fitted to that of AlN, but not of metallic $\mathrm{Al}$ or $\mathrm{Al}_{2} \mathrm{O}_{3}$. Figure 7(c) shows the change of Auger peak shape in a low energy field below $100 \mathrm{eV}$. It

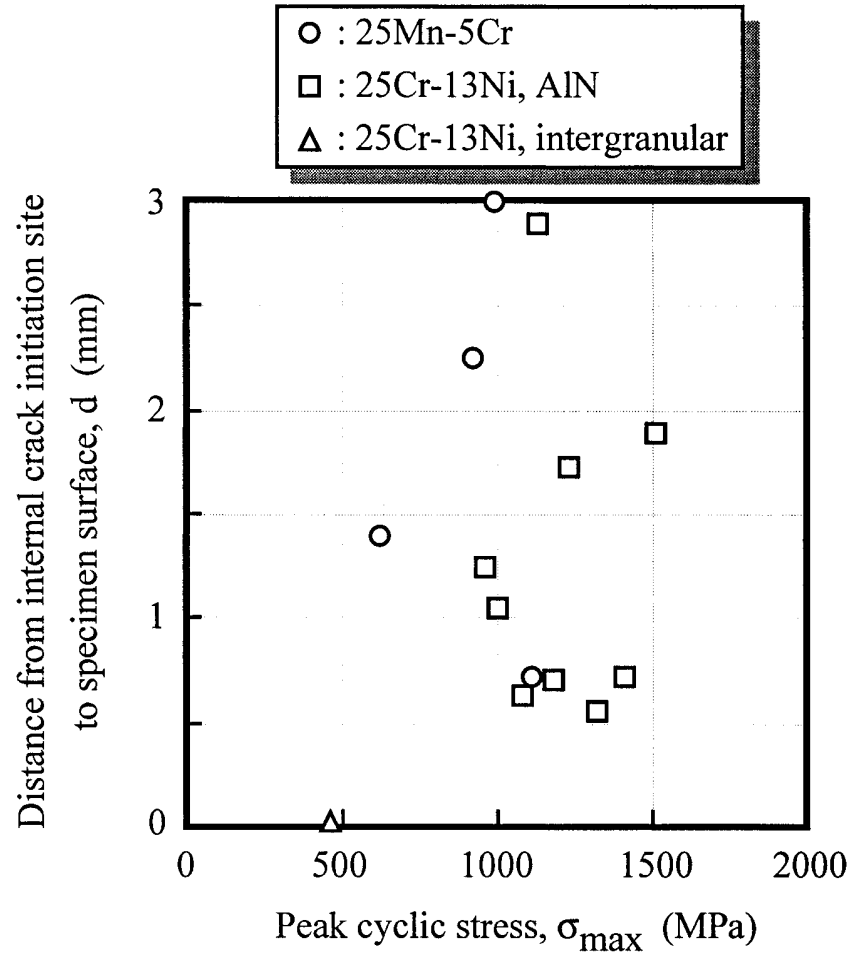

Fig. 8-Location of the internal crack initiation site in each fracture surface for $25 \mathrm{Mn}-5 \mathrm{Cr}$ and $25 \mathrm{Cr}-13 \mathrm{Ni}$ steels.

exhibits that the peak-to-peak height of $\mathrm{Al}$ decreases with sputtering time. On the other hand, those of $\mathrm{Fe}$ and $\mathrm{Cr}$ increase with time.

It is concluded that the defect at the internal crack-initiation site is an AlN precipitate. According to sputteringrate examination for a stainless steel, the thickness of the AlN can be estimated at about $200 \mathrm{~nm}$. The AlN preferably precipitates along prior austenite boundaries. ${ }^{[16]}$ In the present $25 \mathrm{Cr}-13 \mathrm{Ni}$ steel, it has not been determined whether the AlN precipitated at the boundary or not. The internal crackinitiation site of a sample fractured at $293 \mathrm{~K}$, however, exhibited an intergranular form. There was no evidence of the relation with AlN cracking. The surface crack initiation was not related with any pre-existing defects.

\section{B. Location and Size of the Crack Initiation Site Associated with Nonmetallic Particles}

Figure 8 shows the location of the internal crack-initiation sites on the fracture surface. The data plots seem to be scattered over the specimen diameter, although the number of data is not enough. There is no tendency for a favourable depth of the location, as in the case of the Ti-6Al-4V alloys. ${ }^{[17]}$ The location of the sites must be dependent on the location of a fatal defect in each specimen.

Figure 9 shows the dependence of the crack-initiation site size $f_{s}$ on peak cyclic stress for $25 \mathrm{Mn}-5 \mathrm{Cr}$ and $25 \mathrm{Cr}-13 \mathrm{Ni}$ steels. In the present data of $25 \mathrm{Mn}-5 \mathrm{Cr}$ steel, the range of size is between 10 and $40 \mu \mathrm{m}$ for surface defect and between 40 and $100 \mu \mathrm{m}$ for internal defect. The size of the crack-initiation site associated with inclusions $f_{s}$ seems to increase with the decrease of the peak cyclic stress. For the $25 \mathrm{Cr}-13 \mathrm{Ni}$ steel, on the other hand, the $f_{s}$ of the internal crack-initiation-related AlN is equal to about $10 \mu \mathrm{m}$ re- 


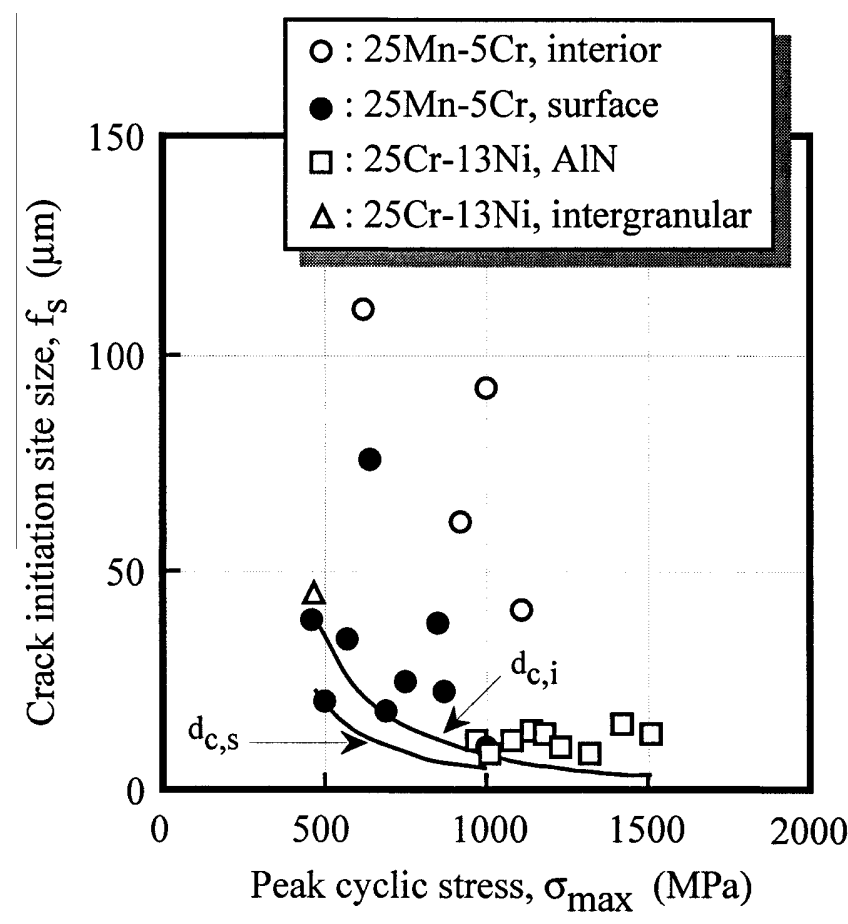

Fig. 9-Size of the internal crack initiation sites and of the surface crack initiation sites associated with an inclusion. Assuming the $\Delta K_{t h}$ value of each steel is equal to $2.5 \mathrm{MPa} \sqrt{\mathrm{m}}$ resulting from Fig. 13, solid lines show the calculated threshold crack initiation site size at specimen surface, $d_{c, s}$, and in specimen interior, $d_{c, i}$.
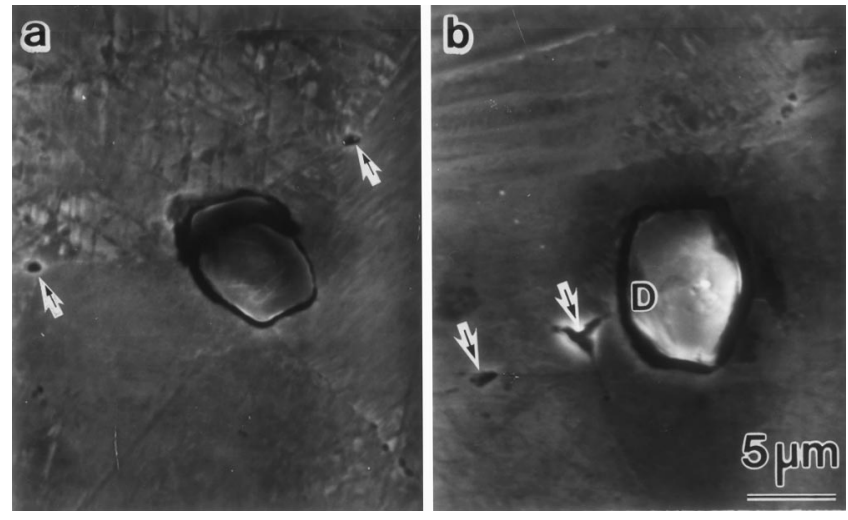

Fig. 10-SEM photographs of debonded inclusions in the longitudinal section, which is from the same plane as in Fig. 4(c): (a) debonded inclusion at which apparent matrix deformation has occurred; and $(b)$ debonded inclusion at which microcracks have linked up to form a tightly closed fatigue crack, which joins the debond seam at D. Arrows indicate microcrackings.

gardless of stress level and test temperature. However, the internal crack initiation in the much lower peak cyclic stress range at $293 \mathrm{~K}$ provided a much larger site with intergranular form instead of the AlN cracking.

\section{DISCUSSION}

\section{A. Fatigue Crack Generation Associated with Nonmetallic Particles in the Specimen Interior}

The adhesion between the matrix and the nonmetallic inclusion, $\mathrm{Al}_{2} \mathrm{O}_{3}$, in the present $25 \mathrm{Mn}-5 \mathrm{Cr}$ steel was weak, as mentioned previously, Although it is not clear that either the cracking of inclusions or the debonding between those and the matrix took place prior to the fatigue test. Such weak adhesion between the matrix and the inclusion produces a local stress raiser. The fatigue crack originates at the periphery of the inclusion regardless of its location in specimen, i.e., specimen surface or interior. The SEI micrographs in Figure 10 represent the debonded small inclusions in the specimen interior after fatigue cycling. In particular, the growing microcrack does not seem to be related to slip band intrusion/extrusion, but rather to the linkup of microcrackings that might be produced by heterogeneous slip deformation. Figure 10(b) shows that microcracks formed at the point defects have linked up to form a tightly closed fatigue crack and to join at D. It is considered that microcracks formed as the debonded seams around the inclusions in the specimen interior would link together and lead to fatigue crack initiation in the matrix. It means that the proposed model to describe the fatigue crack initiation based on debonding of surface inclusions by Lankford and Kusenberger, ${ }^{[4]}$ could be applicable to explain the fatigue crack generation due to nonmetallic inclusions in the specimen interior.

On the other hand, the AlN cracking in $25 \mathrm{Cr}-13 \mathrm{Ni}$ steel would provide a sharp crack with enough size to propagate at a given stress level like microstructural cracking. ${ }^{[6,9]}$ Then the AlN cracking could make the stage I crack itself to start stage II crack propagation. In the present study, there was no evidence of the stage I crack growth from AlN cracking into a matrix to form a larger site.

In both steels, the internal crack initiation associated with defects was dominant at lower temperature and in the subsurface crack initiation due to microstructural cracking. ${ }^{[6,9]}$ In the present study, deformation structures of the fatigued samples were also examined. Figure 11 represents the dislocation pileups for $25 \mathrm{Cr}-13 \mathrm{Ni}$ steel that were sharply localized and caused stress concentration in the vicinity of a grain boundary (GB) in Figure 11(a)). For both steels, (111) co-planar slip prevailed in the lower stress range where the internal crack initiation occurred. The (111) stacking faults in $25 \mathrm{Cr}$-13Ni steel (Figure 11(c)), and $\varepsilon$-martensite and deformation twinning in $25 \mathrm{Mn}-5 \mathrm{Cr}$ steel (Figure 12) were not a major factor in cyclic deformation. Furthermore, the plastic deformation in those steels was highly inhomogeneous. On the other hand, the hard particles, such as $\mathrm{Al}_{2} \mathrm{O}_{3}$ and AlN in the specimen interior, are a kind of obstacle for the dislocation motion in the matrix and can hardly be deformed. Slip deformation in the matrix could occur in the vicinity of such particles. Therefore, the particles do not yield under cyclic deformation, produce stress concentration around themselves, and finally are cracked or debonded with the matrix to relax the stress concentration. Thus, it is considered that the generation of fatigue cracks associated with the nonmetallic particles in the specimen interior involve a highly localized deformation in the vicinity of the particles.

\section{B. Dependence of Pre-existing Defect Size on Stress Range}

Lankford and Kusenberger ${ }^{[4]}$ have reported that the fatigue life in 4340 steel was more closely related to the diameter of inclusions than to whether the nucleating particle was located at the surface or subsurface, and they suggested 

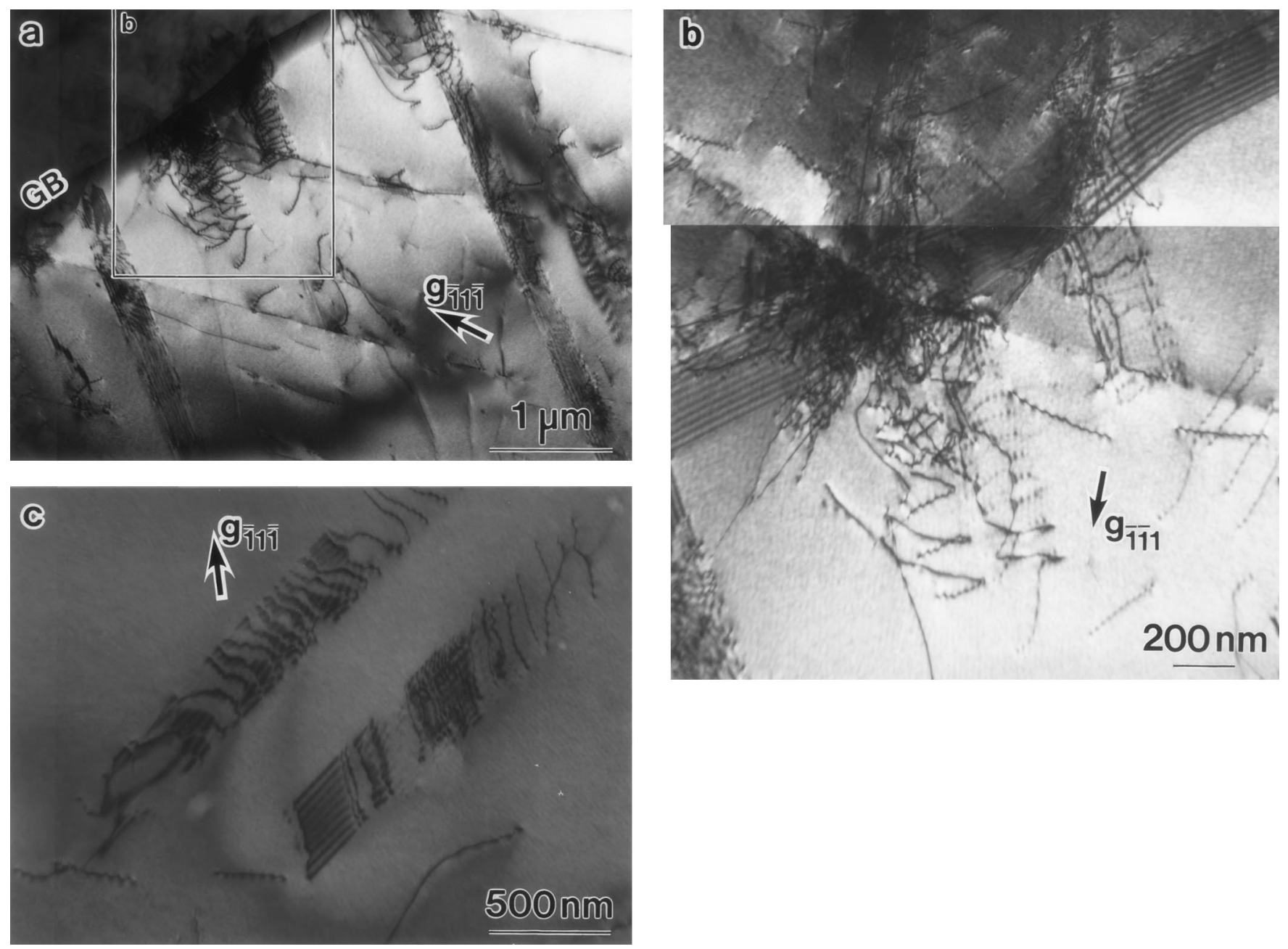

Fig. 11-Dislocation structure of a cyclically deformed $25 \mathrm{Cr}-13 \mathrm{Ni}$ sample at $4 \mathrm{~K}:(a)$ stress amplitude, $\sigma_{a}=485 \mathrm{MPa}$, after $2 \times 10^{6}$ cycles; $(b)$ the magnified image of pileups in (a) with a different two-beam condition; and (c) stress amplitude, $\sigma_{a}=745 \mathrm{MPa}$, after 88,600 cycles. Beam directions are near [011].

that the mechanism of near subsurface crack initiation should be qualitatively similar to that of surface nucleation. Kitagawa et al. ${ }^{[18]}$ and Murakami ${ }^{[19]}$ proposed that the fatigue limit of the material containing pre-existing defects was determined from the relationship between the defect size and threshold stress range. These ideas are based on the assumption that a small defect, such as an inclusion, is equivalent to a microcrack (stage I crack) and that the microcrack growth is retained under the fatigue limit. In the range of $2 a$ (crack length) $>d_{c}$ (threshold defect size), $\Delta \mathrm{K}_{t h}$ value determines the fatigue limit threshold stress range. For $2 a<d_{c}$, on the other hand, the threshold stress range is almost equal to the fatigue limit of the material without defects. However, it should be noted that Kitagawa and Murakami took the defect size as a crack size. Generally the microcrack itself does not always provided a critical main crack size. The microcrack needs to grow until it finally forms the initiation site of a critical size and the stage I crack generation resulting from microstructural crackings. ${ }^{[6,9]}$ It is also necessary to take into account the threedimensional shape of the defect (stage I crack) and of the radius of curvature at the tip. Hence, it may not be true that the defect size is equal to the nucleus of the main crack or the threshold defect size. Especially in the range of $2 a<$

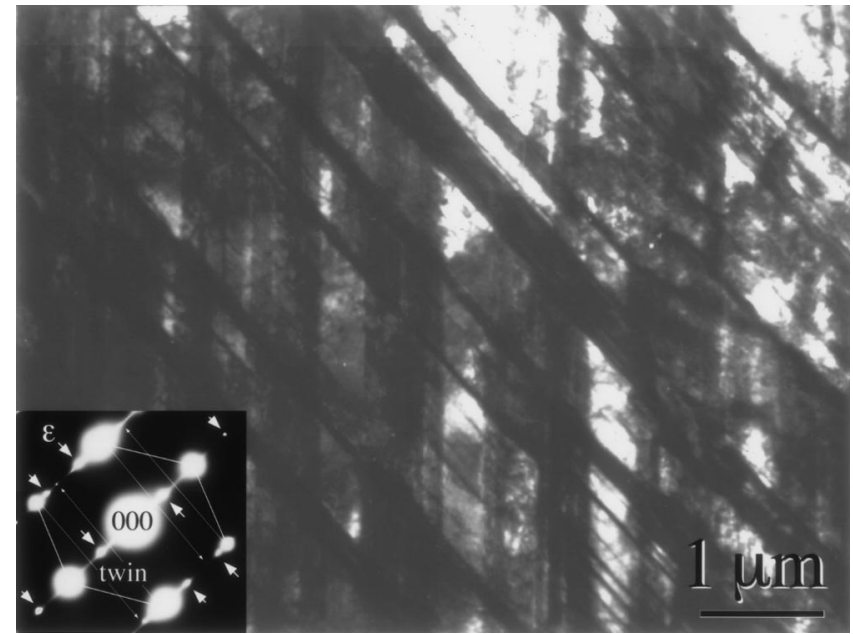

Fig. 12-Deformation structure of a fatigued sample for $25 \mathrm{Mn}-5 \mathrm{Cr}$ steel after 12,390 cycles at $4 \mathrm{~K}\left(\sigma_{a}=666 \mathrm{MPa}\right)$. Selected area diffraction pattern $[0 \overline{1} \overline{1}]_{\gamma}$ zone normal showing the $\varepsilon$ reflections (arrows) and $\{111\}$ twinning reflections.

$d_{c}$, it is considered that the size gap between the postulated nucleus of the main crack and the defect is greater. In the 


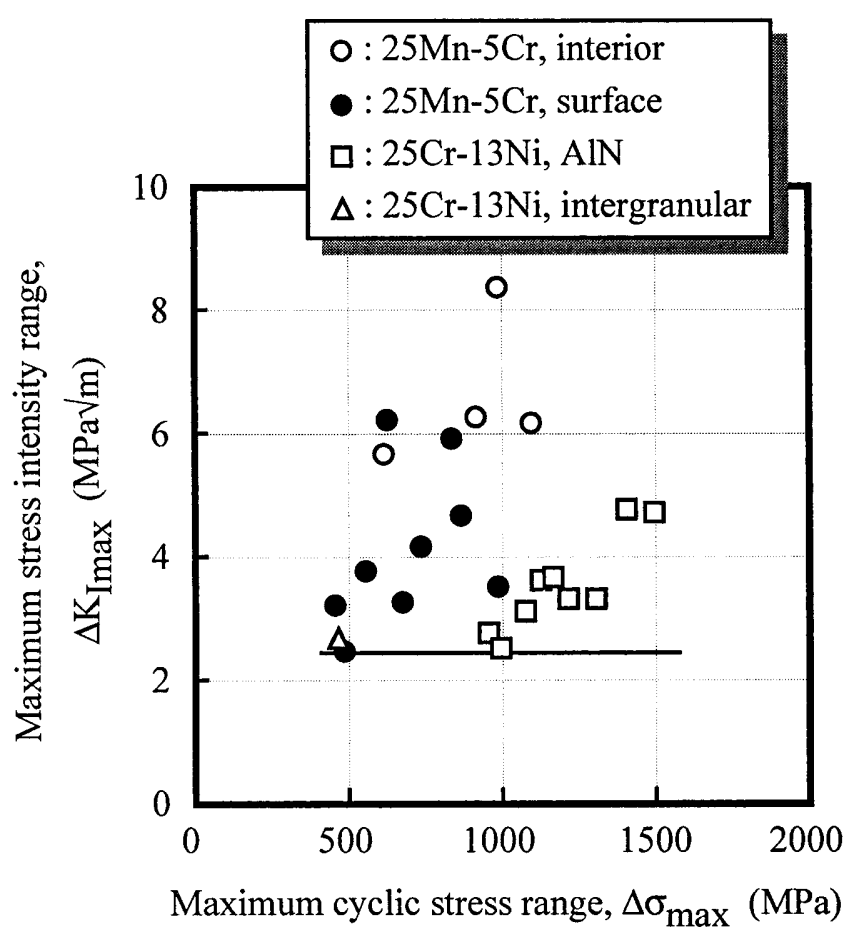

Fig. 13-Relationship between maximum cycle stress range, $\Delta \sigma_{\max }$, and maximum stress intensity factor, $\Delta K_{\text {Imax }}$, for $25 \mathrm{Mn}-5 \mathrm{Cr}$ and $25 \mathrm{Cr}-13 \mathrm{Ni}$ steels.

present study, we adopted the $f_{s}$ defined previously as a crack size parameter. In addition, the deformation mode at the crack tip was simplified into the mode II in stage I and the mode I in stage II.

Then, an approximate equation to give the maximum stress intensity range, $\Delta K_{\text {Imax }}$, at the crack tip is roughly represented as follows:

$$
\begin{aligned}
& \Delta K_{\text {Imax }}=0.65 \Delta \sigma_{\max } \sqrt{\pi f_{s}} \quad: \text { surface defect } \\
& \Delta K_{\text {Imax }}=0.5 \Delta \sigma_{\max } \sqrt{\pi f_{s}} \quad: \text { internal defect }
\end{aligned}
$$

where $\Delta \sigma_{\max }$ is maximum cyclic stress range, and the coefficient in each equation was adopted in the reference. ${ }^{[19]}$ On the basis of the previous assumptions, Figure 13 rearranges the data in Figure 9 and shows the relationship between $\Delta \sigma_{\max }$ and $\Delta K_{\text {Imax }}$. The value of $\Delta K_{\text {Imax }}$ for $25 \mathrm{Mn}-5 \mathrm{Cr}$ steel is in a range between 2.5 and $8.5 \mathrm{MPa} \sqrt{\mathrm{m}}$. On the other hand, the value of $\Delta K_{\text {Imax }}$ for $25 \mathrm{Cr}-13 \mathrm{Ni}$ steel is in a narrower range between 2.5 and $5 \mathrm{MPa} \sqrt{\mathrm{m}}$. The bigger $\Delta K_{\text {Imax }}$ data are considered to exhibit the excess of the crack-initiation site size from a threshold value. Supposing $\Delta K_{t h}=2.5 \mathrm{MPa} \sqrt{\mathrm{m}}$ in each steel, the threshold defect size $d_{c, s}$ (specimen surface) and/or $d_{c, i}$ (specimen interior) are calculated by Eqs. [1] and [2], as shown in Figure 9. It means that a main crack can start to propagate when the $f_{s}$ is greater than $d_{c, s}$ in the specimen surface or $d_{c, i}$ in the specimen interior. Because the $f_{s}$ values and related AIN cracking were around $10 \mu \mathrm{m}$ regardless of stress level for the $25 \mathrm{Cr}-13 \mathrm{Ni}$ steel, it can hardly satisfy the $\Delta K_{t h}$ condition around $\Delta \sigma_{\max }=500 \mathrm{MPa}$. In the case of the internal crack initiation in such a lower peak cyclic stress range, therefore, the intergranular cracking is considered to form the site over a critical size earlier than the AIN cracking. According to the previous discussions, there might be a critical con- dition, $\Delta K_{t h}=$ constant, at any stress level where the crack generation associated with defects occurs along with the subsurface crack initiation resulting from microstructural cracking. ${ }^{[6,9,17]}$ It is suggested that the refinement of the defect size in the present steels is effective to increase their fatigue strength.

\section{CONCLUSIONS}

An investigation has been made on the internal fatigue crack generation associated with nonmetallic particles, such as inclusions or precipitates in high-strength steel, at cryogenic temperatures. The principal results are as follows:

1. The internal crack initiation was dominant at a $4 \mathrm{~K}$ or longer life range over $10^{6}$ cycles in $25 \mathrm{Mn}-5 \mathrm{Cr}$ and $25 \mathrm{Cr}$ $13 \mathrm{Ni}$ steels;

2. The origin of internal crack initiation was $\mathrm{Al}_{2} \mathrm{O}_{3}$ inclusion in $25 \mathrm{Mn}-5 \mathrm{Cr}$ steel and $\mathrm{AlN}$ precipitate in $25 \mathrm{Cr}$ $13 \mathrm{Ni}$ steel, respectively;

3. The generation of fatigue cracks associated with the nonmetallic particles in the specimen interior involved a stage I crack. This suggests that the nature of the internal crack generation process is almost the same with the subsurface crack generation resulting from microcracking in the matrix;

4. The dependence of the internal crack-initiation site size on the peak stress suggests a threshold condition assumption, that the crack propagation occurs at any stress level when the local stress intensity factor range reaches over a constant at or around the initiation crack associated with defects.

\section{ACKNOWLEDGMENTS}

We thank Mr. T. Yuri and Dr. T. Ogata for their help in providing the fatigue data. Thanks are also extended to Dr. M. Imai and Mr. K. Honma for the technical help on SAM and EPMA analyses, respectively.

\section{REFERENCES}

1. T. Abe and K. Kanazawa: Zairyo, 1991, vol. 40, pp. 1147-1452 (in Japanese).

2. C. Masuda, S. Nishijima, H. Sumiyoshi, Y. Tanaka, and A. Ishii: Zairyo, 1985, vol. 34, pp. 664-69 (in Japanese).

3. T. Kunio, M. Shimizu, K. Yamada, K. Sakura, and T. Yamamoto: Int. J. Fract., 1981, vol. 17, pp. 111-19

4. J. Lankford and F.N. Kusenberger: Metall. Trans., 1973, Vol. 4, pp. 553-59.

5. O. Umezawa, K. Nagai, and K.Ishikawa: Mater. Sci. Eng., 1990, vol. 129A, pp. 217-22.

6. O. Umezawa, K. Nagai, and K. Ishikawa: in Fatigue 90, H. Kitagawa and T. Tanaka, eds., MCEP, Birmingham, 1990, vol. 1, pp. 267-72.

7. O. Umezawa, K. Nagai, T. Yuri, T. Ogata, and K. Ishikawa: $A d v$. Cryo. Eng. Mater., Plenum Press, New York, NY, 1992, vol. 38, pp. $175-88$

8. K. Nagai, T. Yuri, O. Umezawa, T. Ogata, and K. Ishikawa: Proc. Stainless Steels 1991, Iron Steel Inst. Jpn., Tokyo, 1991, vol. 1, pp. 465-72.

9. O. Umezawa and K. Nagai: Metall. Mater. Trans, A 1998, vol. 29A, pp. 809-22.

10. T. Yuri, K. Nagai, O. Umezawa, and T. Ogata: Proc. Cryogenic Eng. Conf., Cryogenic Engineering Society of Japan, Tokyo, 1995, vol. 54, p. 125 (in Japanese). 
11. J.-H. Lee, I. Maekawa, H. Shibata, S. Nishida, and G.-N. Kim: Zairyo, 1989, vol. 38, pp. 1176-81, (in Japanese).

12. T. Sakamoto, Y. Nakagawa, I. Yamauchi, S. Shimamoto, and H. Nakajima: Seitetsu-Kenkyu, 1985, No. 318, pp. 28-33 (in Japanese).

13. H. Yoshimura, T. Shimizu, and K. Kitajima: Tetsu-to-Hagané, 1981, vol. 67, pp. 2010-18 (in Japanese)

14. T. Ogata and K. Ishikawa: Trans. Iron Steel Inst. Jpn., 1986, vol. 26, pp. $48-52$.

15. O. Umezawa, K. Nagai, T. Yuri, T. Ogata, and K. Ishikawa: unpublished data.
16. F.G. Wilson and T. Gladman: Int. Mater. Rev., 1988, vol. 33, pp. 221-86

17. H. Yokoyama, O. Umezawa, K. Nagai, and T. Suzuki: Iron Steel Inst. Jap. Int., 1997, vol. 37, pp. 1237-44.

18. H. Kitagawa, S. Takahashi, C.M. Suh, and S. Miyashita: Fatigue Mechanisms, ASTM STP 675, ASTM, Philadelphia, PA, 1978, pp. 420-47.

19. Y. Murakami: Tetsu-to-Hagané, 1989, vol. 75, pp. 1267-77 (in Japanese) 